\title{
Adenosine induced transient cardiac standstill in catheter interventional procedures for congenital heart disease
}

\author{
J V De Giovanni, R A Edgar, A Cranston
}

\begin{abstract}
Objective-To describe the use of intravenous adenosine to create transient cardiac standstill during balloon dilatation procedures for congenital heart defects. Setting-A tertiary paediatric cardiac centre.

Design and patients-This was a prospective pilot study. Thirteen patients born with congenital heart disease and who had stenotic lesions requiring relief were considered for the technique. All were suitable for balloon dilatation. Their ages ranged from 2 months to 30 years, mean (SD) 9.9 (9.8) years. The dose of adenosine varied from $0.125 \mathrm{mg} / \mathrm{kg}$ to $0.555 \mathrm{mg} / \mathrm{kg}$, mean $0.33(0.127)$.

Results-Two patients only developed sinus bradycardia in response to adenosine, which may have been related to the technique of administration. The other 11 experienced a period of asystole, which ranged from 2.4 to 10.8 seconds, mean 4.99 (2.27), and a total atrioventricular block period of 5.0 to 21.2 seconds, mean 9.47 (4.64). The interval between adenosine injection and the onset of asystole varied from 2.4 to 15.8 seconds, mean 8.05 (3.6), depending on cannula size, site of administration, and cardiac output. The peak gradient across the stenotic lesions fell from 52.3 (23.7) to 17.8 (11.9) $\mathrm{mm} \mathrm{Hg}$ $(p<0.001)$. Apart from one short episode of atrial fibrillation there were no complications.
\end{abstract}

Conclusions-Intravenous adenosine is a safe and effective agent for creating transient cardiac standstill during balloon dilatation procedures for congenital heart disease. This achieves stability which is likely to improve results and reduce complications. It may have applications in other fields of cardiac intervention where an immobile heart is desirable during the critical phase of a procedure.

(Heart 1998;80:330-333)

Keywords: adenosine; asystole; balloon dilatation; congenital heart disease

Congenital stenotic lesions of the cardiovascular system involving valves (for example, aortic or pulmonary stenosis) or main vessels (for example, coarctation of the aorta or pulmonary artery stenosis) are treated either by surgery or by catheter interventions such as balloon dilatation or stenting. ${ }^{1-5}$ The role of catheter intervention techniques has increased over the years, forming around $60 \%$ of catheter procedures in some centres. ${ }^{67}$ Cardiac contraction causes movement of the inflated balloon, which may be displaced from the site of stenosis resulting in failure or a suboptimal result. Moreover, such balloon movement during full inflation may cause damage to structures such as valve leaflets or vessel intima. Direct myocardial injury may also result from cardiac contraction against the inflated balloon. Technical modifications such as the use of extra stiff exchange wires or double balloons help to overcome some of these problems but only partly address the issues..$^{8-10}$

The concept of transient cardiac standstill during catheterisation at the time of the inflation procedure is an attractive idea and is likely to improve results and reduce complication rates. We elected to use intravenous adenosine to achieve this because of its short and predictable action. Adenosine, which is a natural purine nucleoside, is known to affect heart rate through the $\mathrm{A} 1$ receptors and to have vasodilator effects through the A2 receptors. ${ }^{11-13}$ The electrophysiological effects of adenosine include sinoatrial block and atrioventricular block. ${ }^{14-16}$ The latter effect is used to terminate supraventricular tachycardia or to unmask the arrhythmia substrate. ${ }^{17}{ }^{18}$ It is this property on the atrioventricular (AV) node that is exploited to create a controlled period of asystole for interventional procedures. Adenosine has the benefit of being a natural product which is rapidly broken down by red blood cells and endothelium and has a half life of around 10 seconds. This guarantees a short period of asystole with a predictable return of spontaneous conduction. The duration of asystole is dose dependent but is also influenced by the rapidity and site of administration, as well as by cardiac output and possibly by some drugs.

\section{Methods}

PATIENTS

Over a three month period, 13 patients scheduled for balloon dilatation for congenital stenotic lesions considered significant on clinical or echocardiographic grounds were given intravenous adenosine during the procedure, to create transient cardiac standstill so that the balloon was not displaced during inflation. There were eight male and five female patients, with ages ranging from 2 months to 30 years, mean (SD) 9.9 (9.8) years. The lesions consisted of aortic stenosis in six, coarctation in three, and right ventricular outflow obstruction
Accepted for publication 18 June 1998 
Table 1 Patient data

\begin{tabular}{lllll}
\hline Patient & Sex & $\begin{array}{c}\text { Age } \\
\text { (years) }\end{array}$ & $\begin{array}{l}\text { Weight } \\
(\text { kg) }\end{array}$ & Diagnosis \\
\hline 1 & M & 12.8 & 32 & AS \\
2 & M & 3.5 & 12 & AS \\
3 & M & 5.5 & 18 & AS \\
4 & F & 8.0 & 17 & AS \\
5 & M & 0.75 & 9 & AS \\
6 & M & 0.17 & 4.86 & PS \\
7 & F & 1.5 & 12.7 & PS \\
8 & M & 2.8 & 51 & Coarctation \\
9 & M & 30 & 94 & Coarctation \\
10 & M & 16.3 & 54 & Coarctation \\
11 & F & 10 & 40 & AS \\
12 & F & 2.3 & 13.1 & PS \\
13 & F & 10.1 & 35 & Conduit calcif
\end{tabular}

AS, aortic stenosis; conduit calcif, calcification of conduit; PS, pulmonary stenosis.

in a further four (three with pulmonary stenosis and one with calcified right ventricle to pulmonary artery homograft) (table 1).

\section{PROTOCOL}

Cardiac catheterisation was performed under general anaesthesia in seven patients and under sedation in the remaining six. Baseline haemodynamic investigations and angiography were performed to confirm the diagnosis, and to establish the indications for dilatation and the choice of balloon size. The latter is based on our department's protocol of using a balloon to lesion diameter ratio of 1:1 for aortic stenosis and coarctation (narrowest native diameter taken) and up to 1.3:1 for pulmonary stenosis. A femoral vein cannula or a $4 \mathrm{~F}$ catheter placed in the right atrium was used so that the adenosine could be given rapidly. The initial adenosine dose was $0.1 \mathrm{mg} / \mathrm{kg}$ but the length of asystole created was not sufficiently long and the initial dose was increased to $0.3 \mathrm{mg} / \mathrm{kg}$ in subsequent cases. Larger doses may be required to achieve the desired period of asystole, which should ideally last from five to 10 seconds.

Inspired oxygen was increased to prime the circulation. The balloon was partially inflated with dilute contrast before the adenosine administration to confirm that the stenotic lesion was at the centre of the balloon.

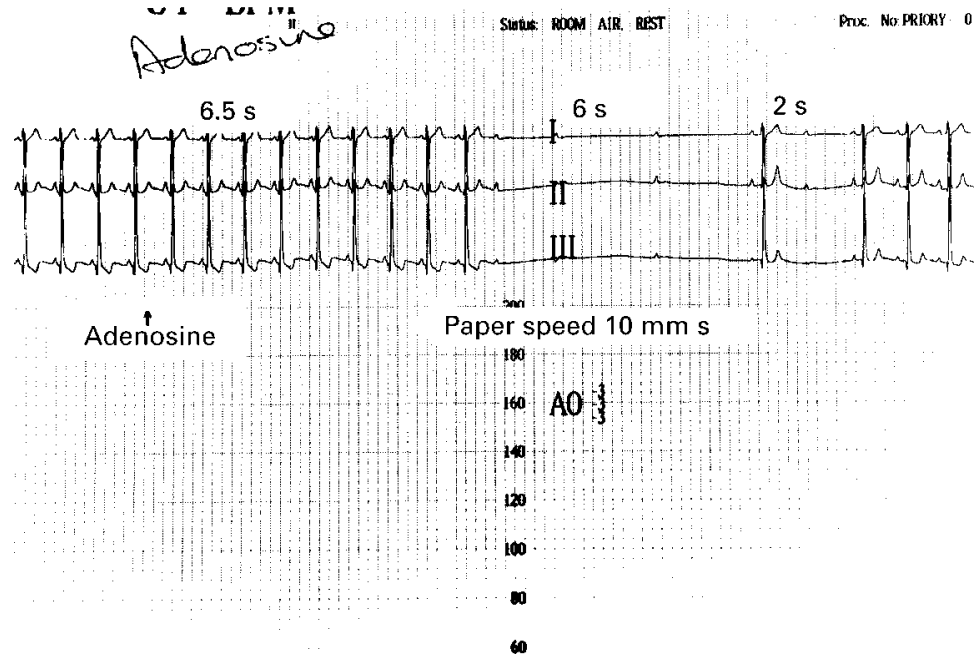

Figure 1 ECG following adenosine administration in patient 10 with the interval between administration and asystole of 6.5 seconds, an asystole time of 6 seconds, and a total atrioventricular block of 8 seconds.
Intravenous adenosine was then injected rapidly, followed by a saline flush; this often resulted in a short period of sinus bradycardia followed by asystole. At this point, the balloon was fully inflated with abolition of waist formation followed by quick deflation. The effect of the dilatation was then assessed by measuring the gradient using a Multi-Track angiographic catheter (MAP Medical Equipment Inc, New York, USA) and, in cases of aortic stenosis and coarctation, aortography was performed to document the presence and extent of aortic regurgitation or aortic dissection. If the result was suboptimal, the procedure was repeated, if necessary using a larger balloon, and using adenosine for the repeat procedure. A result was considered satisfactory if the gradient was reduced by more than $50 \%$, if there was angiographic improvement, or both.

\section{MEASUREMENTS}

For the purpose of this study the dose of adenosine was calculated in $\mathrm{mg} / \mathrm{kg}$. The heart rate response to adenosine was measured on ECG paper recorded at 10 or $25 \mathrm{~mm} / \mathrm{s}$. The interval between adenosine administration and the onset of $\mathrm{AV}$ block was noted as was the duration of asystole and the total period of second or third degree AV block (fig 1). Pulse oximetry and blood pressure were also monitored.

\section{STATISTICAL ANALYSIS}

Data are expressed as mean (SD). The asystole/AV block values relate only to the 11 patients who responded favourably to adenosine. Haemodynamic observations before and after balloon dilatation were compared using Student's $t$ test. A probability (p) value of $<0.05$ was considered significant.

\section{Results}

The effect of adenosine ranged from sinus bradycardia in two patients (both of whom had pulmonary stenosis and in whom a 21 gauge cannula was used), to AV block in the other 11 . The dose of adenosine ranged from 0.125 $\mathrm{mg} / \mathrm{kg}$ to $0.555 \mathrm{mg} / \mathrm{kg}$, mean (SD) 0.329 (0.127). Ten patients received one dose, two received two doses, and one had three doses. The interval from the administration of adenosine to asystole ranged from 2.4 to 15.8 seconds, mean 8.05 (3.6). The length of asystole, which was measured from the last QRS complex to the first conducted beat, ranged from 2.4 to 10.8 seconds, mean 4.99 (2.27), and the period of AV block (second or third degree) ranged from 5.0 to 21.2 seconds, mean 9.47 (4.64). The only rhythm disturbance following adenosine was a brief episode of self terminating atrial fibrillation in patient 9 , which lasted for 37 seconds during which time the patient remained haemodynamically stable. This was an adult patient with coarctation, in whom the guidewire had inadvertently entered the right coronary artery during balloon inflation. Occasional ventricular premature beats were noted when the balloon was inflated within the ventricle in two patients, one with aortic and one with pulmonary stenosis, 
Table 2 Adenosine response and haemodynamic result

\begin{tabular}{|c|c|c|c|c|c|c|c|c|}
\hline \multirow[b]{2}{*}{ Patient } & \multirow{2}{*}{$\begin{array}{l}\text { Adenosine } \\
(\mathrm{mg} / \mathrm{kg})\end{array}$} & \multirow{2}{*}{$\begin{array}{l}\text { No of } \\
\text { doses }\end{array}$} & \multirow[b]{2}{*}{$G A /$ sed } & \multirow{2}{*}{$\begin{array}{l}\text { Duration to } \\
\text { asystole }(s)\end{array}$} & \multirow{2}{*}{$\begin{array}{l}\text { Asystole time } \\
\text { (s) }\end{array}$} & \multirow{2}{*}{$\begin{array}{l}\text { AV block } \\
\text { duration (s) }\end{array}$} & \multicolumn{2}{|c|}{$\begin{array}{l}\text { Peak systolic gradient } \\
(m m \mathrm{Hg})\end{array}$} \\
\hline & & & & & & & Pre & Post \\
\hline 1 & 0.375 & 1 & GA & 10 & 4.6 & 8 & 84 & 9 \\
\hline 2 & 0.25 & 1 & Sed & 5 & 4.4 & 7.4 & 60 & 44 \\
\hline 3 & 0.222 & 1 & Sed & 5.4 & 3.8 & 6.7 & 79 & 34 \\
\hline 4 & 0.294 & 3 & Sed & 8 & 4.2 & 9.3 & 102 & 28 \\
\hline 5 & 0.555 & 1 & Sed & 7.6 & 4.2 & 8.5 & 40 & 13 \\
\hline 6 & 0.417 & 1 & GA & \multicolumn{2}{|c|}{ Sinus bradycardia } & & 35 & 7 \\
\hline 7 & 0.215 & 1 & GA & \multicolumn{2}{|c|}{ Sinus bradycardia } & & 32 & 8 \\
\hline 8 & 0.235 & 1 & Sed & 11.5 & 2.6 & 6.8 & 63 & 18 \\
\hline 9 & 0.125 & 2 & Sed & 7 & 2.4 & 5 & 30 & 6 \\
\hline 10 & 0.22 & 1 & GA & 6.5 & 6 & 8 & 25 & 12 \\
\hline 11 & 0.33 & 1 & GA & 9.4 & 6.2 & 15.1 & 45 & 20 \\
\hline 12 & 0.458 & 1 & GA & 2.4 & 4.7 & 8.2 & 40 & 7 \\
\hline 13 & 0.514 & 2 & GA & 15.8 & 10.8 & 21.2 & 45 & 25 \\
\hline
\end{tabular}

GA, general anaesthesia; sed, sedation.

although these were isolated and occurred at the beginning of the inflation without displacing the balloon. There were no other complications (table 2).

There was haemodynamic improvement in all patients, with a fall in peak gradient from a mean of 52.3 (23.7) to 17.8 (11.9) $\mathrm{mm} \mathrm{Hg}$ $(\mathrm{p}<0.001)$. Two patients with pulmonary stenosis developed only mild pulmonary regurgitation detectable on Doppler with no right ventricular dilatation or dysfunction following pulmonary valvoplasty. Of the six patients with aortic stenosis, one had mild aortic regurgitation and the rest had trivial or no regurgitation. None developed severe regurgitation. The three patients with coarctation had a good haemodynamic and angiographic result, with no dissection or aneurysm formation; two of these patients had the procedure performed under sedation and one experienced only mild chest pain, whereas the other had no discomfort at all during angioplasty. This is an interesting observation as most patients experience quite severe chest pain during balloon inflation, and it raises the issue as to whether the pain is caused by stretching of the aorta or by movement of the inflated balloon causing shear stress injury; if it is the latter, this may have implications with regard to intimal tears.

In patient 13, who had a calcified homograft between the right ventricle and pulmonary artery for pulmonary atresia/ventricular septal defect repair, the technique was used in the hope that stability of the balloon would prevent balloon rupture from movement against calcium spicules. Despite achieving a good period of asystole and balloon stability, however, the balloon burst with minimum pressure owing to the presence of sharp calcified edges.

All had postoperative echocardiography/ Doppler studies that were consistent with the results recorded at the time of catheterisation.

There was no apparent awareness of the period of asystole in those patients who had the procedure under sedation. There were no neurological symptoms or signs at the time or after the procedure.

\section{Discussion}

Balloon dilatation is a recognised and, in many instances, a preferred method of treatment for congenital stenotic lesions such as pulmonary/ aortic valve stenosis or coarctation. Achieving balloon stability by creating transient cardiac standstill ensures that the stenosed segment is at the centre of the balloon and that it is not displaced by cardiac contraction. This should lead to a better haemodynamic outcome and possibly fewer complications. Moreover, if balloon stability is achieved with such a technique, a shorter balloon can be used effectively with the potential benefit of less injury to the myocardium or the aortic wall.

Complications of balloon valvoplasty for congenital/pulmonary stenosis include valvar regurgitation and this is more relevant for the aortic valve. Possible mechanisms causing regurgitation include cusp perforation, leaflet tears, or leaflet avulsion. Factors which determine outcome include valve morphology, valve size, and the size of balloon used. An oversized balloon, in particular, is a recognised risk factor as a cause of aortic regurgitation..$^{19}{ }^{19}$ Leaflet avulsion damage, provided that the correct size of balloon is used, is likely to be caused by extrusion of the inflated balloon across the stenosed valve by the hypertrophied and hyperkinetic ventricle. Manoeuvres to prevent balloon movement by cardiac contraction during inflation include the use of extra stiff wires or double balloons when the retrograde approach is used ${ }^{8}$; ; an alternative technique is to cross the aortic valve antegradely using a trans-septal approach with the intention of using traction to prevent balloon movement, but this has been associated with damage to the mitral valve. ${ }^{90}$ Although the traction method is effective for pulmonary stenosis, there is potential for damage to the pulmonary and the tricuspid valves as a result of balloon movement, although right sided problems are better tolerated.

Arterial stenosis dilatation is also associated with complications including dissection, ${ }^{21}$ rupture, and aneurysm formation, depending on the morphology and aetiology of the stenosis as well as the choice of balloon size. An additional reason for damage to the vessel wall may be the drag force created by the inflated balloon as it is being pushed by blood during cardiac contraction. This may have an influence on complications such as rupture/dissection, and our observation that the level of pain in the two patients with coarctation was much less than 
usual when balloon inflation was carried out with cardiac standstill may support this.

Apart from damage to the stenosed structures, myocardial damage may result from myocardial contraction against an acute obstruction created by the inflated balloon, further increasing wall stress. Moreover, further direct damage to the myocardium may result from contraction against an inflated balloon for patients with semilunar valve stenosis, where part of the balloon is situated within the ventricular cavity which is often small owing to physiological hypertrophy. Transient asystole should reduce this level of damage, although it may be difficult to quantitate such a reduction.

Creating temporary cardiac standstill can be achieved using several agents. In the early days of angiography, before the availability of catheters for selective coronary imaging, acetylcholine was used at the time of aortography to fill the coronary arteries. Although this technique worked, it was unpredictable and dangerous. We feel that adenosine is a safe and predictable agent to create transient cardiac standstill as it is metabolised by erythrocytes and the endothelium within seconds, producing a short period of asystole with a prompt and guaranteed return of cardiac contraction. Although this technique has been used to place aortic stents in a limited number of patients, ${ }^{22} 23$ and to create controlled hypotension for cerebral aneurysm surgery, ${ }^{24}$ it has not been described in the context of congenital heart defects, especially for valvar stenotic lesions and in children. If the duration of asystole needs to be longer, a larger dose of adenosine can be used although this may have to be titrated before the interventional procedure to make sure that the duration of asystole is acceptable. For the procedures we have carried out, a period of asystole of between five and 10 seconds is sufficient for balloon inflation and deflation, although longer periods may be necessary and can be achieved for some procedures such as stent implantation. Some drugs such as dipyridamole ${ }^{25}$ potentiate the effect of adenosine, whereas xanthines are competitive antagonists. It is therefore important to take this into account when using the procedure. Although we have not had to pace any of the patients, it would be prudent to have a temporary pacing system available in the event of prolonged asystole, although this should not happen with the doses recommended. We do know from the use of adenosine in electrophysiological work that pacing is effective in adenosine induced asystole.

\section{STUDY LIMITATIONS}

The patient numbers were too small to compare results and complications with similar groups where the asystole technique was not used. Dose titration, which we did not carry out routinely, may also be advisable in order to achieve a predictable period of asystole for individual patients.

\section{CONCLUSIONS}

We recommend this simple technique of creating transient cardiac standstill for interven- tional procedures in congenital heart disease that involve the heart valves and great arteries, and where balloon stability during inflation simplifies the technique and may improve results and reduce complications. In this limited study it has proved safe. It may also be of benefit for other interventions where it is desirable to have asystole during the critical phase of an interventional procedure.

We wish to thank Dr S P Singh of the City Hospital, Birmingham and Dr Masood Sadiq of the Punjab Institute of Cardiology, Lahore, Pakistan for agreeing to have their patients included in this study.

1 McCrindle BW. Independent predictors of immediate results of percutaneous balloon aortic valvuloplasty in childhood. Am f Cardiol 1996;77:286-293.

2 Lock JE, Bass JL, Castaneda-Zuniga W, et al. Dilatation angioplasty of congenital or operative narrowings of venous channels. Circulation 1984;70:457-64.

3 O'Laughlin MP, Slack MC, Grifka RG, et al. Implantation and intermediate-term follow-up of stents in congenital heart disease. Circulation 1993;82:605-14.

4 Zeevi B, Berant M, Bleiden LC. Midterm clinical impact versus procedural success of balloon angioplasty for versus procedural success of balloon angioplasty for
pulmonary artery stenosis. Pediatr Cardiol 1997;18:101-6. pulmonary artery stenosis. Pediatr Cardiol 1997;18:101-6.
Radtke WA. Interventional pediatric cardiology: state of the art and future perspective. Eur F Pediatr 1994;153:542-7.

6 Verma R, Keane F. Percutaneous therapy of structural heart disease: pediatric disease. Prog Cardiovasc Dis 1997;40:3754.

7 Gatzoulis MA, Rigby ML, Redington AN. Interventional catheterisation in paediatric cardiology. Eur Heart $\mathcal{f}$ 1995;16:1767-72.

8 Mullins CE, Nihill MR, Vick GW, et al. Double balloon technique for dilatation of valvular or vessel stenosis in congenital and acquired heart disease. $f \mathrm{Am}$ Coll Cardiol 1987;10:107-14

9 Sholler GF, Keane JF, Perry SB, et al. Balloon dilatation of congenital aortic stenosis-results and influence of technical and morphological features on outcome. Circulation 1988;78:351-60.

10 Vogel M, Benson LN, Burrows P, et al. Balloon dilatation of congenital aortic valve stenosis in infants and children: short term and intermediate results. Br Heart $\mathcal{F}$ 1989;62: 148-53.

11 Belardinelli L, Lindley J, Berne RM. The cardiac effects of adenosine. Prog Cardiovasc Dis 1989;32:73-97.

12 Aggarwal A, Warltier DC. Adenosine: present uses, future indictions. Curr Opin Anesthesiol 1994;7:109-22.

13 Pelleg A, Belardinelli L. Adenosine and the treatment of supraventricular tachycardia. Cardiovasc Res 1993;27:54-61.

14 Drury AN, Szent-Gyorgyi A. The physiological action of adenine compounds with special reference to their action upon the mammalian heart. F Physiol (Lond) 1929;68:21337.

15 Wayne EJ, Goodwin JF, Stoner HB. The effect of adenosine triphosphate on the electrocardiogram of man and animals. Br Heart f 1949;11:55-67.

16 Favale S, Di Biase M, Rizzo V, et al. The effect of adenosine and adenosine-5-triphosphate on atrio-ventricular conduction. F Am Coll Cardiol 1985;5:1212-19.

17 Di Marco J, Sellers TD, Lerman BB, et al. Diagnostic and therapeutic use of adenosine in patients with supraventricular tachyarrhythmias. F Am Coll Cardiol 1985;6:417-25.

18 Griffith MJ, Linker NJ, Ward D, et al. Adenosine in the diagnosis of broad complex tachycardia. Lancet 1988;i:672-5.

19 Waller BF, Girod DA, Dillon JC. Transverse aortic wall tears in infants after balloon angioplasty for aortic valve stenosis: relation of aortic wall damage to diameter of inflated angioplasty balloon and aortic lumen in seven necropsy cases. $\mathcal{F}$ Am Coll Cardiol 1986;4:1235-41.

20 Magee AG, Nykanen D, McCrindle BW, et al. Balloon dilatation of severe aortic stenosis in the neonate: comparison of antegrade and retrograde catheter approaches. $7 \mathrm{Am}$ Coll Cardiol 1997;30:1061-6.

21 Sohn S, Rothman A, Shiota T, et al. Acute and follow-up intravascular ultrasound findings after balloon dilatation of intravascular ultrasound findings after balloon dilatation

22 Dorros G, Cohn JM. Adenosine-induced transient cardiac asystole enhances precise deployment of stent-grafts in the thoracic and abdominal aorta. F Endovasc Surg 1996;3: $270-2$.

23 Baker AB, Bookallil MJ, Lloyd G. Intentional asystole during endoluminal thoracic aortic surgery without cardiopulmonary bypass. Br f Anaesth 1997;78:444-8.

24 Sollevi A, Lagerkrauser M, Irestect L, et al. Controlled hypotension with adenosine in cerebral aneurysm surgery. Anesthesiology 1984;61:400-5.

25 Watt AH, Bernard MS, Webster J, et al. Intravenous adenosine in the treatment of supraventricular tachycardia; a dose sine in the treatment of supraventricular tachycardia; a dose
ranging study and interaction with dipyridamole. $\mathrm{Br}$ f Clin Pharmacol 1986;21:227-30. 